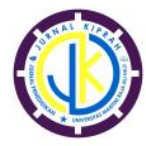

http://ojs.umrah.ac.id/index.php/kiprah

p-ISSN 2354-7278 | e-ISSN 2580-6947

\title{
Efektivitas Media BIGVU pada Pembelajaran Jurnalistik dalam Meningkatkan Keterampilan Newscaster Mahasiswa PBSI
}

\author{
Sisi Rosida* \\ Saintek, Universitas Pembangunan Panca Budi, Medan, Indonesia \\ Pengiriman: 22/04/2021; Diterima: 21/06/2021; Publikasi: 29/06/2021 \\ DOI: 10.31629/kiprah.v9i1.3237
}

\begin{abstract}
Abstrak
Teknologi digital membuka ruang bagi mahasiswa menjalankan aktivitas jurnalistik. Ilmu jurnalistik dan bahasa berkaitan dengan public speaking mendorong mahasiswa PBSI menguji keterampilan berbahasanya. Tujuan penelitian ini mengetahui keefektifan BIGVU pada mata kuliah jurnalistik, sebagai media peningkatan keterampilan newscaster mahasiswa PBSI. Jenis Penelitian ini adalah penelitian kuantitatif, menggunakan preexperimental designs, dalam bentuk one-goup pretest-postes design. Metode pengumpulan data menggunakan penugasan dalam bentuk video. Adapun temuan penelitian (1) BIGVU meningkatkan keterampilan newscaster, dibuktikan dari pengingkatan hasi belajar, pada posttest sebesar 82,8, sedangkan pretest hanya sebesar 69,9. (2) BIGVU digunakan sebagai media pembelajaran jurnalistik meningkatkan keterampilan newscaster terbilang efektif, dibuktikan dari hasil perbandingan nilai t-hitung $(9,6)$ lebih besar dari pada t-tabel $(1,6736)$.
\end{abstract}

Kata kunci: BIGVU; jurnalistik; mahasiwa PBSI; newscaster; public speaking,

\begin{abstract}
The digital technology opened for students who carry out journalistic activities. Journalism and language sciences related to the public speaking to encourage PBSI students to test their language skills. The purpose of this study was to determine the effectiveness of BIGVU in journalism courses, as a media for improving the skills of newscaster students of PBSI. This type of research is a quantitative study, using pre-experimental designs, in the form of one-goup pretest-posttest design. The data collection method uses an assignment in the form of a video. The research findings (1) BIGVU improved newscaster skills, as evidenced by the increase in posttest learning outcomes of 82.8, meanwhile pretest was only 69.9. (2) BIGVU is used as a journalistic learning media to improve newscaster skills which is considered effective, as evidenced by the comparison of the value of $t$-hitung $(9.6)$ is greater than $t$-tabel (1.6736).
\end{abstract}

Keywords: BIGVU; journalism; news caster; PBSI's collage student; public speaking

\section{PENDAHULUAN}

Jurusan Pendidikan Bahasa Indonesia (PBSI) merupakan bidang yang mengajarkan keterampilan berbahasa Indonesia dengan baik dan efektif. Meluasnya prospek kerja di jurusan PBSI tidak hanya sebagai guru semata, melainkan menjadi seorang peneliti, pengajar BIPA, dan jurnalis. Tentu keberhasilan mahasiswa sebagai tolak ukur dalam proses perkuliahan, menuju prospek kerja berkualitas. Pengetahuan dan keterampilan saja dinilai belum maksimal, dibutuhkan adanya praktik yang memadai. Hal ini guna pemenuhan profil lulusan PBSI dalam bidang jurnalistik yang dinilai masih sempit. Menindaklanjutinya, prodi PBSI mengadakan kebijakan mengenai praktik mata kuliah jurnalistik, bertujuan agar mahasiswa dapat terjun langsung menyiarkan 
berita di beberapa stasiun televisi lokal.

Kebijakan ini, tentunya menjadi momok besar bagi mahasiswa semester VI. Hal ini dibuktikan penuhnya kotak "Kritik dan Saran" yang berisi keluhan mereka. Jika dicermati, sebagian besar berisi keluhankeluhan mengenai rendahnya keterampilan mahasiswa dalam meliput dan menyiarkan berita yang menjadi aspek pentik sebagai bekal praktik di lapangan.

Ditelaah lebih jauh, kemampuan jurnalisme mahasiswa PBSI terbilang rendah. Selama ini, keberhasilan pembelajaran jurnalistik dinilai sebatas teori menulis berita. Beberapa mahasiswa semester VI mengungkapkan hal yang sama, saat dimintai wawancara kecil. Mereka menilai mata kuliah jurnalistik hanya sebatas "numpang lewat", sejatinya banyak keterampilan-keterampilan penting yang harus dikuasai agar membuka peluang kerja. Dunia jurnalistik erat kaitannya dengan kegiatan penyampaian informasi kepada khalayak umum melalui media massa. Hal ini bersinggungan dengan publik atau khalayak umum, dibutuhkan keterampilan tambahan untuk mencapai kolaborasi efektif antara teori dan praktik.

Untuk menyikapi keluhan mahasiwa, dibutuhkan adanya media pembelajaran pada mata kuliah jurnalistik guna mempersiapkan bekal praktik di lapangan. Hal ini merupakan tantangan bagi pengajar, membentuk prospek kerja profesional yang menguasai soft skills maupun hard skills.

(Martono, 2020) jurnalistik merupakan lapangan pekerjaan baru bagi mahasiswa bahasa dan sastra Indonesia. Para mahasiswa berpeluang menjadi jurnalis, jika mereka tidak berkeinginan menjadi seorang guru. Keterbatasan daya serap untuk menjadi guru, harus sudah diperhatikan oleh LPTK. Lulusan PBSI dapat bekerja di dunia persuratkabaran dan pertelevisian yang bisa menjadi profil lulusan. Oleh karena itu, pentingnya peran kurikulum menciptakan lulusan yang terampil memenuhi prospek kerja. Adanya penambahan mata kuliah berhubungan dengan jurnalistik, seperti teknologi informasi, berita, feature, redaksi, dan kemampuan dalam menyiarkan berita.

Jurnalistik sendiri diartikan sebagai seluk beluk terkait suatu kegiatan penyampaian suatu gagasan dan informasi pada khalayak luas atau massa melalui jenis media komunikasi seperti media cetak, media elektronik, dan film (Ramadhan, 2018).

Jurnalistik era digital senantiasa mendukung perluasan yang inovatif, memiliki paradima yang kreatif membentuk keterampilan. Diperlukan penggunaan sumber belajar digital dinilai dipengaruhi oleh persepsi pendidik tentang digital natives (Nurdyansyah, 2019). Sumber belajar berkaitan dengan segala sesuatu dalam format digital yang dapat dimanfaatkan oleh guru dan siswa untuk tujuan pembelajaran. Sebagaimana manusia dan digital yang mengubah kehidupan, termasuk inovasi dalam proses pembelajaran (Mila Roysa, 2020).

Ditinjau dari tahun sebelumnya, mata kuliah jurnalistik berpusat media koran sebagai sumber berita. Di mana mahasiswa sebagai subjek dan koran sebagai patron menulis. Perkembangan zaman menuntut mahasiswa aktif memanfaatkan teknologi, tidak hanya berpusat sebagai penulis berita. Dibutuhkan keterampilan di bidang olah informasi dan penyiar berita (newscaster)

Untuk menyiasati problematika skill mahasiswa, diperlukan penggunaan aplikasi BIGVU sebagai media pembentuk keterampilan. Salah satu skill yang ingin dibangun dalam mata kuliah jurnalistik adalah keterampilan newscaster (Suparni, 2015).

Pemanfaatan aplikasi BIGVU bertujuan memudahkan mahasiswa dalam mengolah berita serta melakukan penyiaran berita. BIGVU merupakan aplikasi pengial baca online atau alat bantu baca khususnya bagi seseorang yang ingin mengasah kemapuan berbicara atau presentasi di depan umum. Berbantuan BIGVU, pengguna dapat mengolah informasi, membacakannya dengan media teks berjalan, serta mempublikasikan berita pada laman media sosial. Berbantuan visual teks berjalan inilah pengguna dapat menyesuaikan mimik wajah di layar perekam, praktis untuk menciptakan kontak mata dengan audience.

Pada dasarnya BIGVU sering digunakan sebagai self-jounal, memungkinkan penyebaran info dari sumber pribadi. Terdapat 
fitur note untuk membuat catatan berita dan kartu indeks ke presentasi. Memuat siaran langsung pada layar rekam dengan teks berjalan yang dapat diatur kecepatannya, sehingga melatih kemampuan newscaster.

BIGVU memungkinkan pengguna untuk menyisipkan latar belakang kustom, logo, gambar, dan video, sebagai bahan presentasi. Terdapat fitur note untuk membuat catatan berita dan kartu indeks ke presentasi. Pada aplikasi ini juga terdapat penambahan overlay text pada video yang direkam seperti presenter yang melakukan siaran langsung atau presentasi. Melatih kemampuan newscaster, mahasiswa dapat mengunduh gratis BIGVU pada smartphone sebagai pemanfaatan teleprompter sederhana.

Salah satu alat bantu dalam bidang penyiaran berita adalah teleprompter. (Anggraini dan Manaf, 2019) sejarah teleprompter berupa gulungan kertas "digulir" di depan pembaca berita, untuk "mendorong" suatu dialog. Saat ini teleprompter mengacu pada monitor di bawah sepotong kaca balok diabadikan dalam plastik hitam. Kemudian, kamera ditempatkan di belakang kaca pembagi melalui cermin. Teleprompter dihubungkan ke komputer yang menjalankan perangkat lunak memantulkan gambar cermin dari sebuah teks berjalan yang dipakai oleh pembawa berita (Budyatna, 2014).

Ada tiga kategori pembawa berita, yakni pembaca berita (newsreader), penyiar berita (newscaster), dan jangkar berita (newsanchor). Newscaster adalah orang yang membawakan acara berdasarkan berita, yang disertai para narasumber terkait. Presenter penyaji berita memiliki kelebihan-kelebihan, baik fisik maupun kecerdasan, keberanian dan keterampilan berbahasa.

Menurut Liliweri (Ramadhan \& Caropeboka, 2018) penyaji berita newscaster adalah orang yang membawakan suatu program siaran atau membacakan informasi yang disebarluaskan kepada pendengar melalui media elektronik. Seorang newscaster mengharuskan mempunyai kemampuan untuk menyajikan dan berbicara, terutama dalam mengeluarkan gagasan atau pendapat. Hal ini bertujuan agar pendengar tidak hanya mendengarkan siaran berita, tetapi menjadikan penyiar sebagai opinion leader dalam bertukar informasi.

Salah satu keterampilan yang harus dikuasai seorang presenter adalah keterampilan berbicara. Keterampilan berbicara merupakan kemampuan mengungkapkan informasi, pikiran, dan gagasan khalayak secara lisan. Hafied (2012:73) Ada beberapa aspek ketrampilan bahasa yaitu: menyimak, berbicara, dan menulis. Keterampilan berperan,bagi kelancaran tugas newscaster pada penyiaran TV. Karakteristik yang harus dimiliki seorang newscaster, yaitu: memilih topik yang tepat, menguasai materi pembicaraan, bertugas kontak dengan penonton melalui kamera, sarat kemampuan linguistik, dan menguasai alat bantu (Nuriadi., 2008).

Pembelajaran jurnalistik menggunakan BIGVU diharapkan memberi peran pada keterampilan newscaster mahasiswa PBSI, agar membentuk lulusan yang terampil dalam bidang-bidang prospek kerjanya.

\section{METODE PENELITIAN}

Penelitian ini merupakan jenis penelitian kuantitatif. Desain penelitian ini menggunakan pre-experimental designs, dalam bentuk satu kelompok (the one group pretest-posttest). (Sugiyono, 2008) Pre-Experimental Designs hasil eksperimen merupakan variabel dependen itu bukan semata mata dipengaruhi oleh variabel indipenden. Pada one-group pretest-postest design ini terdapat pretest sebelum diberi perlakuan. Dengan demikian hasil perlakuan dapat diketahui lebih akurat, karena dapat membandingkan dengan keadaan sebelum diberi perlakuan dan sesudah diberi perlakuan (Arikunto, 2010)

Populasi penelitian meliputi seluruh mahasiswa PBSI semester V (lima) Universitas Negeri Medan berjumlah 162 orang. Pengambilan sampel penelitian menggunakan total sampling (sampling jenuh), dengan jumlah 54 orang. Sudjana (20163:7) instrumen penelitian berupa projek 
penugasan menyajikan berita. Penugasan berupa penyajian dan penyiaran berita dalam bentuk video. Adapaun indikator penilaian tugas, yakni: (1) Kemampuan menyampaikan berita, (2) Keefektifan berita, (2) Esensi dan kuliatas isi bahasan, (4) Lokasi caster dalam penyiaran berita. Analisis data penelitian, untuk mengetahui perbandingan hasil belajar mahasiswa pada pretest-posttest, menganalisis data dengan uji normalitas data dan uji homogenitas, kemudian perhitungan uji-t dengan sebagai pembuktian hipotesis.

\section{HASIL DAN PEMBAHASAN}

Temuan pada penelitian ini diperoleh hasil belajar mahasiswa PBSI semester V (ganjil), berupa video penyajian berita sebagai praktik newscaster yang diukur pada pretest dan posttest. Kemudian, hasil belajar siswa akan dianalisis menggunakan uji-t, yang sebelumnya dilakukan uji normalitas dan uji homogenitas data. Berikut data-data hasil belajar mahasiswa pretest dan posttest.

\section{Hasil Penelitian}

Tabel 1. Ringkasan Hasil Belajar

\begin{tabular}{llll}
\hline No. & Statistik & Pretest & Postest \\
\hline 1. & Jumlah siswa & 54 & 54 \\
2. & Jumalah nilai & 3776 & 4473 \\
3. & Nilai rata-rata & 69,9 & 82,8 \\
\hline
\end{tabular}

Berdasarkan data hasil belajar di atas, dapat di distribusikan sebagai berikut:

Tabel 2. Hasil Belajar Pretest

\begin{tabular}{llll}
\hline Interval & $\begin{array}{l}\text { Tingkat } \\
\text { Kemampuan }\end{array}$ & F & Persentase \\
\hline $\mathbf{5 0 - 5 9}$ & Sangat Rendah & 6 & $11,1 \%$ \\
$\mathbf{6 0 - 6 9}$ & Rendah & 32 & $59,3 \%$ \\
$\mathbf{7 0 - 7 9}$ & Sedang & 10 & $18,5 \%$ \\
$\mathbf{8 0 - 8 9}$ & Tinggi & 4 & $7,4 \%$ \\
$\mathbf{9 0 - 1 0 0}$ & Sangat Tinggi & 2 & $3,7 \%$ \\
& & 54 & $100 \%$ \\
\hline
\end{tabular}

Dari di hasil belajar di atas menunjukkan minimnya kemapuan newscaster mahasiswa PPBSI. Hal ini dibuktikan dengan banyaknya mahasiswa yang memiliki tingkat kemampuan rendah sebesar 59,3\%, sedangkan mahasiswa dengan tingkat kemampuan tinggi hanya 3,7\%.
Menyikapi persoalan hasil belajar, dilakukan perlakuan berupa penggunaan BIGVU pada mata kuliah Jurnalistik. Adapun hasil belajar siswa setelah perlakuan pada tahap posttest, yaitu:

Tabel 3. Hasil Belajar Prosttest

\begin{tabular}{llll}
\hline Interval & $\begin{array}{l}\text { Tingkat } \\
\text { Kemampuan }\end{array}$ & F & Persentase \\
\hline $\mathbf{9 0 - 1 0 0}$ & Sangat Tinggi & 21 & $11,1 \%$ \\
$\mathbf{8 0 - 8 9}$ & Tinggi & 12 & $59,3 \%$ \\
$\mathbf{7 0 - 7 9}$ & Sedang & 8 & $18,5 \%$ \\
$\mathbf{6 0 - 6 9}$ & Rendah & 10 & $7,4 \%$ \\
$\mathbf{5 0 - 5 9}$ & Sangat Rendah & 3 & $3,7 \%$ \\
& & 54 & $100 \%$ \\
\hline
\end{tabular}

Distribusi hasil belajar setelah menggunakan BIGVU mengalami perubahan yang signifikan. Mahasiswa dengan tingkat kemampuan rendah sekitar 3,7\%, lebih kecil dari hasil pretest. Kemudian mahasiswa dengan tingkat kemampuan kategori sangat tinggi sebanyak $21 \%$, lebih banyak dari hasil pretest. Menganalisis hasil belajar anatra pretest dan posttest dapat dilihat melalui perbandingan grafik berikut ini:

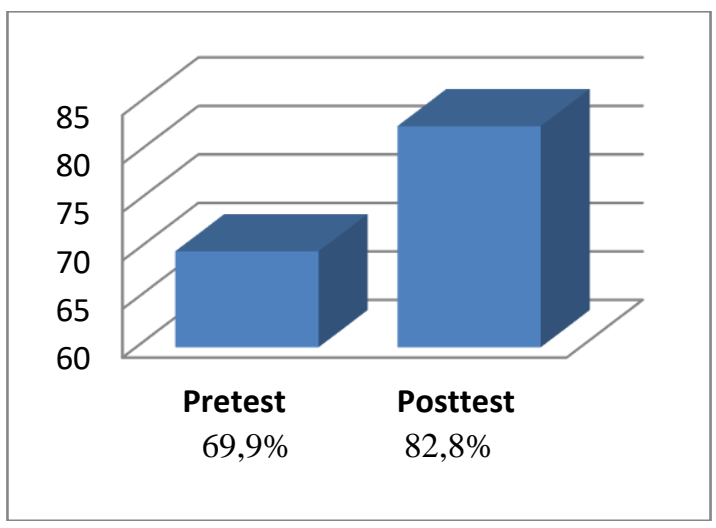

Gambar 1. Perbandingan Hasil Pretest dan Posttest

Diagram di atas menunjukkan terjadi peningkatan nilai siswa dari sebelum dan setelah diberikan perlakuan. Dengan demikian dapat dikatakan bahwa terdapat peningkatan hasil belajar siswa. Data yang diperoleh selanjutnya dilakukan uji normalitas data dan homogenitas data untuk menguji hipotesis. Perbandingan pretest-posttest di atas diuji keabsahannya melalui perhitungan berikut: 
Tabel 4. Hasil Nilai Rata-rata dan Standar Deviasi

\begin{tabular}{|c|c|c|c|c|c|c|}
\hline Kode & $\mathrm{X}_{1}$ & $\mathrm{X}_{2}$ & $X_{1}^{2}$ & $\mathrm{X}_{2}^{2}$ & D1 & D2 \\
\hline R01 & 75 & 100 & 5625 & 10000 & 25 & 625 \\
\hline R02 & 88 & 100 & 7744 & 10000 & 12 & 144 \\
\hline R 03 & 89 & 100 & 7921 & 10000 & 11 & 121 \\
\hline R 04 & 50 & 68 & 2500 & 4684 & 18 & 324 \\
\hline R 05 & 54 & 59 & 2916 & 3481 & 5 & 25 \\
\hline R 06 & 68 & 69 & 4900 & 4761 & 1 & 1 \\
\hline R 07 & 56 & 59 & 3136 & 3481 & 3 & 9 \\
\hline R 08 & 80 & 100 & 6400 & 10000 & 20 & 400 \\
\hline R 09 & 60 & 78 & 3600 & 6084 & 18 & 324 \\
\hline R 10 & 70 & 79 & 4624 & 6241 & 9 & 81 \\
\hline R 11 & 68 & 78 & 4624 & 6084 & 10 & 100 \\
\hline R 12 & 59 & 59 & 3481 & 3481 & 0 & 0 \\
\hline R 13 & 68 & 78 & 4624 & 6084 & 10 & 100 \\
\hline R 14 & 68 & 69 & 4624 & 4761 & 1 & 1 \\
\hline R 15 & 60 & 68 & 3600 & 4624 & 8 & 64 \\
\hline R 16 & 58 & 78 & 3364 & 6084 & 20 & 400 \\
\hline R 17 & 68 & 70 & 4624 & 4900 & 2 & 4 \\
\hline R 18 & 78 & 80 & 6084 & 6400 & 2 & 4 \\
\hline R 19 & 68 & 75 & 4624 & 5625 & 7 & 49 \\
\hline R 20 & 57 & 60 & 3249 & 3600 & 3 & 9 \\
\hline R 21 & 78 & 78 & 6084 & 6084 & 0 & 0 \\
\hline R 22 & 68 & 69 & 4624 & 4761 & 1 & 1 \\
\hline R 23 & 78 & 94 & 6084 & 8836 & 16 & 256 \\
\hline R 24 & 78 & 94 & 6084 & 8836 & 16 & 256 \\
\hline R 25 & 68 & 90 & 4624 & 8280 & 22 & 484 \\
\hline R 26 & 68 & 69 & 4624 & 4761 & 1 & 1 \\
\hline R 27 & 79 & 86 & 6241 & 7396 & 7 & 49 \\
\hline R 28 & 68 & 68 & 4624 & 4624 & 0 & 0 \\
\hline R 29 & 69 & 90 & 4761 & 8280 & 21 & 441 \\
\hline R 30 & 64 & 90 & 4096 & 8280 & 26 & 676 \\
\hline R 31 & 69 & 89 & 4761 & 7921 & 20 & 400 \\
\hline R 32 & 78 & 94 & 6084 & 8836 & 16 & 256 \\
\hline R 33 & 60 & 68 & 3600 & 4624 & 8 & 64 \\
\hline R 34 & 69 & 86 & 4761 & 7396 & 17 & 289 \\
\hline R 35 & 78 & 90 & 6084 & 8280 & 12 & 144 \\
\hline R 36 & 64 & 80 & 4096 & 6400 & 16 & 256 \\
\hline R 37 & 68 & 88 & 4624 & 7744 & 20 & 400 \\
\hline R 38 & 64 & 86 & 4096 & 7396 & 22 & 484 \\
\hline R 39 & 68 & 80 & 4624 & 6400 & 12 & 144 \\
\hline R 40 & 68 & 80 & 4624 & 6400 & 12 & 144 \\
\hline R 41 & 66 & 69 & 4356 & 4624 & 3 & 9 \\
\hline R 42 & 78 & 90 & 6084 & 8280 & 12 & 144 \\
\hline R 43 & 66 & 92 & 4356 & 8464 & 26 & 676 \\
\hline R 44 & 66 & 92 & 4356 & 8464 & 26 & 676 \\
\hline R 45 & 68 & 90 & 4624 & 8280 & 22 & 486 \\
\hline R 46 & 68 & 98 & 4624 & 9604 & 30 & 900 \\
\hline R 47 & 68 & 92 & 4624 & 8464 & 24 & 576 \\
\hline R 48 & 90 & 100 & 8100 & 10000 & 10 & 100 \\
\hline R 49 & 68 & 88 & 4624 & 7744 & 20 & 400 \\
\hline R 50 & 88 & 100 & 7744 & 10000 & 12 & 144 \\
\hline R 51 & 68 & 94 & 4624 & 8836 & 26 & 676 \\
\hline R 52 & 100 & 100 & 10000 & 10000 & 0 & 0 \\
\hline R 53 & 68 & 86 & 4624 & 7396 & 18 & 324 \\
\hline R 54 & 68 & 86 & 4624 & 7396 & 18 & 324 \\
\hline $\mathrm{Jlh}$ & 3776 & 4473 & 268828 & 379462 & 679 & 12965 \\
\hline
\end{tabular}

Tabel di atas menunjukkan perbedaan nilai pretest dan nilai posttest. Nilai pretest 66,8 dengan SD 6,7> nilai posttest 87 dengan SD 7,4. Berdasarkan perbandingan tabel, diartikan bahwa adanya peningkatan pada hasil belajar yang dapat diterima dan dapat dilanjutkan pada perhitungan keberhasilannya (uji persyaratan dan pembuktian hipotesis).

Tabel 5. Hasil Uji persyaratan dan Taraf Signifikan

\begin{tabular}{llllll}
\hline No. & $\begin{array}{l}\text { UJI } \\
\text { DATA }\end{array}$ & N & SD & $\mathbf{X}_{\text {hitung }}$ & $\begin{array}{l}\text { Taraf } \\
\text { Signifikan }\end{array}$ \\
\hline 1. & Pretest & 54 & 9,5 & 69,9 & 0,05 \\
2. & Posttest & 54 & 13 & 82,8 & 0,05 \\
\hline
\end{tabular}

Data yang telah melalui proses uji persyaratan, selanjutnya dilakukan pengujian signifikansi adalah dengan menggunakan rumus t-hitung. Berdasarkan perhitungan yang telah dilakukan, di peroleh nilai t-hitung $=9,6$ dan $t_{\text {tabel }}=1,6736$. Perbandingan besarnya $t$ yang diperoleh dalam perhitungan yang tercantum pada nilai $t$ hitung lebih besar dari pada $t_{\text {tabel }}\left(t_{\text {hitung }}>t_{\text {tabel }}\right)$ dimana ( $t_{\text {hitung }} 9,6,>$ 1,6736 $\left.t_{\text {tabel }}\right)$, maka hipotesis diterima.

\section{Pembahasan Hasil Penelitian}

Temuan penelitian ini menunjukkan keterampilan newscaster mahasiswa PBSI diukur menggunakan pretest dan posttest berupa video penyiaran berita. Adapun proses test hasil belajar, yaitu: (1) mahasiswa meliput berita ke suatu tempat, (2) mahasiswa mencatat, meneliti, dan menyusun berita, (3) mahasiswa membaca berita. Adapun hasil belajar mahasiswa menunjukkan pengetahuan yang berbeda pada keterampilannya masingmasing.

Hal ini diketahui pada hasil pretest dengan rata-rata 69,9. Dianalisis dari hasil belajar, pretest, mahasiswa belum mampu mengkomunikasikan berita yang telah diliputnya. Dari rekaman, mahasiswa cenderung gagap dalam menyampaikan berita, bahkan beberapa ada yang terlihat lupa. Sehingga informasi tidak tersampaikan dengan baik.

Setelah mengetahui hasil pretest, peneliti memberikan perlakuan (treatment) berupa media BIGVU yang disosialisasikan penggunaannya dalam mata kuliah Jurnalistik. 
Dianalisis dari adanya perlakuan mahasiswa PBSI menggunakan aplikasi BIGVU dalam menyiarkan berita, pada hasil belajar posttest mahasiswa memperoleh nilai rata-rata 82,8. Setelah menggunakan aplikasi BIGVU, keterampilan mahasiswa meningkat signifikan. Hasil belajar menunjukkan mahasiswa PBSI sangat lancar mengomunikasikan berita. Pada saat siaran berlangsung penyiar berita tampak berkonsentrasi penuh. Selain itu, tampilan informasi leboh menarik karena memanfaatkan fitur-fitur pada aplikasi BIGVU, dengan demikian berita tersampaikan dengan jelas dan efektif. Hal ini membuktikan bahwa keterampilan newscaster mahasiswa meningkat.

Mahasiswa termotivasi untuk belajar dengan bantuan smartphone berperan sebagai teleprompter pintar. Pemanfaatan BIGVU mengatur kelancaran, kenyamanan, dan kelangsungan informasi. Dalam hal ini untuk mencerdaskan masyarakat sebagai penonton dan si penyaji berita sebagai pelaksana program. Pengaturan BIGVU dapat diatur berdasarkan kecepatan membaca seseorang, hal ini agar lebih mudah dalam mengimplementasikannya. Kebermanfaatan media ini dibuktikan dengan cepatnya pengiriman video hasil belajar, bahkan beberapa mahasiswa mengunggah video berita mereka pada laman media sosialnya masingmasing.

Hal ini diyakini membangun keterampilan menyaiarkan berita, meliputi: (1) keterampilan menyimak, sebagai kemampuan umtuk membahas, mengembangkan topik, dan permasalahan berita. (2) keterampilan dalam berbicara, untuk mengungkapkan pendapat dan pikiran sebagai transformasi informasi. (3) keterampilan membaca berita, terkait melafalkan dengan intonasi jelas, sehingga berita dapat dipahami, dan (4) keterampilan menulis, dilakukan dalam merumuskan materi sesuai topik berita (Erka, 2015).

Penelitian serupa dilakukan (Hadiono, 2019) ada pengaruh yang signifikan antara mata kuliah jurnalistik terhadap minat mahasiswa KPI IAIDA menjadi jurnalis, hal ini dapat dilihat dari uji korelasi Pearson Product Moment yang tergolong kuat sebesar 44,89\%. Pada uji signifikansi, t-hitung lebih besar dari t-tabel $(3,831>1,734)$, yang menunjukkan data signifikan.

Efektivitas adalah untuk mengetahui apakah tujuan belajar telah tercapai secara efektif atau tidak, maka dapat diketahui dengan tingkat prestasi atau hasil dari belajar yang telah dicapai. tingkat keberhasilan dapat dibagi atas beberapa tingkatan atau taraf yaitu istimewah (maksimal), baik sekali (optimal), baik (minimal), dan kurang (Syaiful Bahri Djamarah, 2002).

Berdasarkan penelitian, tingkat prestasi belajar mahasiswa PBSI berada dalam katagori "optimal", karena menunjukkan peningkatan belajar yang signifikan sebesar 12,3\%. Keberhasilan BIGVU meningkatkan keterampilan newscaster mahasiswa PBSI dapat disimpulkan dari telaah data melalui proses uji validitas yang berlanjut ke pengujian hipotesis. Ditemukan perbandingan bahwa ( $\mathrm{t}_{\text {hitung }}$ 9,6 > 1,6736 $\mathrm{t}_{\text {tabel }}$ ) yang menyatakan hipotesis diterima. karena $t$-hitung lebih besar dari pada $\mathrm{t}_{\text {-tabel, }}$ maka hipotesis diterima dan penelitian ini signifikan. Disimpulkan bahwa BIGVU terbilang efektif dalam meningkatkan keterampilan newscaster mahasiswa PBSI dalam mata kuliah jurnalistik.

\section{KESIMPULAN}

Hasil penelitian ini ditinjau dari hasil pretest dan posttest. Mahasiswa yang tidak menggunakan BIGVU dalam pembelajaran jurnalistik, rata-rata memiliki keterampilan newscaster dengan kategori rendah, sedangkan mahasiswa yang menggunakan BIGVU mendapat peningkatan keterampilan yang signifikan, baik ditinjau dari keterampilan berbicara, membaca, dan publikasi. Selanjutnya, peningkatan keterampilan newscaster menggunakan media BIGVU lebih tinggi secara signifikan dibandingkan dengan pembelajaran tanpa menggunakan media. Hasil penelitian ini membuktikan bahwa BIGVU terbilang efektif meningkatkan keterampilan newscaster mahasiswa PBSI.

Berkaitan dengan itu, peneliti memberikan saran bahwa dosen dapat menggunakan media BIGVU dalam mata kuliah Jurnalistik untuk meningkatkan keterampilan newscaster mahasiswa. Sebaiknya media ini hendaknya diterapkan dalam waktu yang lebih lama agar mahasiswa mendapat pelatihan yang memadai mengenai pemanfaatan media secara detail, sehingga keterampilan newscaster mahasiswa lebih tinggi dan menarik. 


\section{UCAPAN TERIMAKASIH}

Artikel ini merupakan publikasi hasil penelitian dosen. Oleh karena itu, penulis mengucapkan terimakasih kepada pihak-pihak yang terkait mensukseskan penelitian ini.

\section{REFERENSI}

Abdi Fauji Hadiono. (2019). Studi Pengaruh Mata Kuliah Jurnalistik Terhadap Minat Mahasiswa KPI IAIDA Blokagung Banyuwangi Menjadi Jurnalis. Journal of Chemical Information and Modeling, 53(9), 1689-1699.

Ahsin, M. N., \& Fathurohman, I. (2020). Penerapan Blended Learning dengan Moodle dan Media Website dalam Pembelajaran Jurnalistik Daring. Sasando: Jurnal Bahasa, Sastra Indonesia, dan Pengajarannya Lembaga Penelitian dan Pengabdian Masyarakat Universitas Pancasakti Tegal, 3(2), 33-46.

Anggraini, D., Abdul Manaf, N., \& R, S. (2019). Kontribusi Pengetahuan Jurnalistik Terhadap Keterampilan Menulis Berita Mahasiswa. Komposisi: Jurnal Pendidikan Bahasa Sastra Dan Seni, 20(1), 56--67. http://ejournal.unp.ac.id/index.php/kom posisi/article/view/102888

Arikunto. (2010). Prosedur Penelitian (Rineka Cip).

Asadi, R., Trinh, H., Fell, H. J., \& Bickmore, T. W. (2017, November). IntelliPrompter: speech-based dynamic note display interface for oral presentations. In Proceedings of the 19th ACM International Conference on Multimodal Interaction (pp. 172-180).

Cangara Hafied. (2012). Pengantar Ilmu Komunikasi (PT Raja Gr).

De Jong, F., Ordelman, R., \& Huijbregts, M. (2006, December). Automated speech and audio analysis for semantic access to multimedia. In International Conference on Semantic and Digital Media Technologies (pp. 226-240). Springer, Berlin, Heidelberg.

Erka, W. (2015). Keterampilan Berbahasa Presenter Penyaji Berita pada Lembaga
Penyiaran Televisi. Jurnal Ipteks

Terapan, 8(4), 235-241. https://doi.org/10.22216/jit.2014.v8i4.19

Gasser, E., Ahn, B., Napoli, D. J., \& Zhou, Z. L. (2019). Production, perception, and communicative goals of American newscaster speech. Language in Society, 48(2), 233-259.

Goring, P. (2004). The rhetoric of sensibility in eighteenth-century culture. Cambridge University Press.

Jacobs, R. N. (1996). Producing the news, producing the crisis: narrativity, television and news work. Media, Culture \& Society, 18(3), 373-397.

Martono. (2020). Pontianak Pos, Borneo Tribun, Tribun Pontianak, Equator, Metro, Berkat, Media Kalbar, Kapuas Pos, Mediator .

Meltzer, K. (2010). TV news anchors and journalistic tradition: How journalists adapt to technology. Peter Lang.

Mila Roysa, M. N. A. (2020). Inovasi Pembelajaran Digital Menggunakan Model Poepada Mata Kuliah Jurnalistik di Prodi PBSI Universitas Muria Kudus. Susando, 3.

Montgomery, M., \& Shen, J. (2017). Direct address and television news-reading: Discourse, technology and changing cultural form in Chinese and western TV news. Discourse, Context \& Media, 17, 30-41.

Muhammad, Prof. Dr.Budyatna, M. A. (2014). Jurnalistik Teori dan Praktik. Remaja Rosdakarya.

Nurdyansyah. (2019). Media Pembelajaran Inovatif (Vol. 4, Issue 3). UMSIDA Press.

http://eprints.umsida.ac.id/id/eprint/667 4

Nuriadi. (2008). Teknik Jitu Menjadi Pembaca Terampil. Pustaka Pelajar.

Olson, J., Ouyang, Y., Poe, J., Trantham, A., \& Waterman, R. W. (2012). The Teleprompter Presidency: Comparing O bama's Campaign and Governing Rhetoric. Social Science Quarterly, 93(5), 1402-1423.

Ramadhan, M., \& Caropeboka, R. M. (2018). Penerapan Kode Etik Jurnalistik oleh 
Penyiar pada Siaran RRI Warta Berita Pro 1 Palembang. 12, 59-72.

Roysa, M., \& Ahsin, M. N. (2020). Inovasi Pembelajaran Digital Menggunakan Model Poe pada Mata Kuliah Jurnalistik di Prodi PBSI Universitas Muria Kudus. Sasando: Jurnal Bahasa, Sastra Indonesia, dan Pengajarannya Lembaga Penelitian dan Pengabdian Masyarakat Universitas Pancasakti Tegal, 3(2), 99-107.

Saputra, A. W. (2015). Pengembangan blog menulis berita untuk majalah sekolah sebagai media pembinaan ekstrakurikuler jurnalistik bagi siswa SMA. KEMBARA: Jurnal Keilmuan Bahasa, Sastra, dan Pengajarannya (eJournal), 1(2), 117-126.

Sari, S. D. (2016). Peningkatan Keterampilan Menulis Teks Berita Melalui Model Think Talk Write dengan Pemanfaatan
Media Kliping Foto Jurnalistik pada Siswa Kelas VIII C SMP Negeri 8 Batang. Jurnal Pendidikan Bahasa dan Sastra Indonesia, 5(1).

Stephenson, A., Reese, D., \& Beadle, M. (2012). Broadcast announcing worktext: A media performance guide. Routledge. Sudjana, N. (2016). No Title. In Penilian Hasil Proses Belajar Mengajar. Remaja Rosdakarya.

Sugiyono. (2008). Metode penelitian pendidikan:(pendekatan kuantitatif, kualitatif dan $R \quad \& \quad D$ ). Alfabeta. https://scholar.google.com/citations?use $\mathrm{r}=\mathrm{uUII} u j$ UAAAAJ $\& \mathrm{hl}=\mathrm{en}$

Syaiful Bahri Djamarah. (2002). Strategi Belajar Mengajar. PT Rineka Cipta.

White, T. (2012). Broadcast news writing, reporting, and producing. Routledge. 